\title{
Article \\ A Novel Synthetization Approach for Multi Coupled Line Section Impedance Transformers in Wideband Applications
}

\author{
Nan Zhang ${ }^{1}\left(\mathbb{D}\right.$, Xiaolong Wang ${ }^{1,2, *}$, Chunxi Bao ${ }^{1}$, Bin Wu ${ }^{1}$, Chun-Ping Chen ${ }^{3, *}$, Zhewang Ma ${ }^{4}$ and Geyu Lu ${ }^{1}$ \\ 1 College of Electronic Science and Engineering, Jilin University, 2699 Qianjin Street, Changchun 130012, China; \\ zhangn19@mails.jlu.edu.cn (N.Z.); chunxibao96@163.com (C.B.); irvinwubin@163.com (B.W.); \\ lugy@jlu.edu.cn (G.L.) \\ 2 International Center of Future Science, Jilin University, 2699 Qianjin Street, Changchun 130012, China \\ 3 Department of Electrical, Electronics and Information Engineering, Kanagawa University, \\ 3-27-1 Rokkakubashi, Kanagawa-ku, Yokohama 221-8686, Japan \\ 4 Graduate School of Science and Engineering, Saitama University, 255 Shimo-Okubo, Sakura-ku, \\ Saitama 338-8570, Japan; maz@mail.saitama-u.ac.jp \\ * Correspondence: Brucewang@jlu.edu.cn (X.W.); chen@kanagawa-u.ac.jp (C.-P.C.)
}

check for updates

Citation: Zhang, N.; Wang, X.; Bao,

C.; Wu, B.; Chen, C.-P.; Ma, Z.; Lu, G. A Novel Synthetization Approach for Multi Coupled Line Section Impedance Transformers in Wideband Applications. Appl. Sci. 2022, 12, 875. https://doi.org/ 10.3390/app12020875

Academic Editors: Atsushi Mase and Neville C. Luhmann

Received: 14 December 2021

Accepted: 12 January 2022

Published: 15 January 2022

Publisher's Note: MDPI stays neutral with regard to jurisdictional claims in published maps and institutional affiliations.

Copyright: (c) 2022 by the authors. Licensee MDPI, Basel, Switzerland. This article is an open access article distributed under the terms and conditions of the Creative Commons Attribution (CC BY) license (https:// creativecommons.org/licenses/by/ $4.0 /)$.

\begin{abstract}
In this paper, a novel synthetization approach is proposed for filter-integrated wideband impedance transformers (ITs). The original topology consists of $N$ cascaded coupled line sections (CLSs) with $2 N$ characteristic impedance parameters. By analyzing these characteristic impedances, a Chebyshev response can be derived to consume $N+2$ design conditions. To optimize the left $N-2$ variable parameters, CLSs were newly substituted by transmission lines (TLs) to consume the remaining variable parameters and simplify the circuit topology. Therefore, there are totally $2 N-N-2$ substituting possibilities. To verify the proposed approach, 25 cases are listed under the condition of $N=5$, and 7 selected cases are compared and discussed in detail. Finally, a 75-50 $\Omega$ IT with $100 \%$ fractional bandwidth and $20 \mathrm{~dB}$ bandpass return loss (RL) is designed and fabricated. The measured results meet the circuit simulation and the EM simulation accurately.
\end{abstract}

Keywords: Chebyshev response; coupled line section (CLS); transmission line (TL); wideband impedance transformer

\section{Introduction}

Impedance transformers (ITs) have been widely used in microwave circuits and systems as a basic circuit component [1]. A diagram of the typical end-fed antenna system is shown in Figure 1, where the IT is used to match the antenna impedance to the coax line impedance (usually $50 \Omega$ ). Many IT and filter structures have been developed in recent years [2-13], and multi-function ITs which are integrated by filters [14-20], phase shifters [21], power dividers [22], and antennas [23] have also been widely researched.

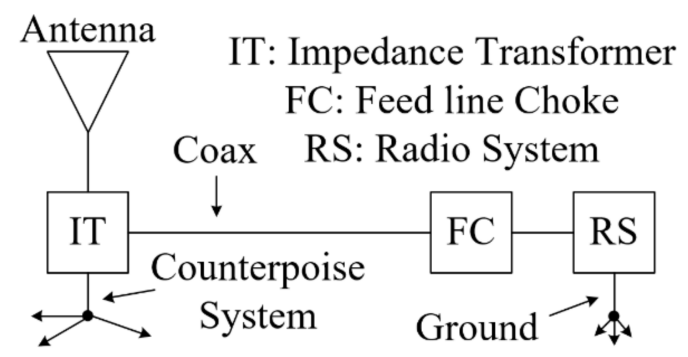

Figure 1. The diagram of typical end-fed antenna system.

In [2,3], a quarter-wave IT is presented using transmission lines (TLs) for single-band applications with a limited operating range. Several IT structures have been designed to 
meet the requirements of multi-band communication systems [4-9], in which multi-section structures are an effective way to design multi-band systems and match impedance [4-7]. Inserting open/short stubs is also available to realize impedance matching [8,9].

In wideband IT applications, filter-integrated ITs have been proposed and developed in recent years to enhance the out-band suppression and reduce the circuit size $[14,16-20]$. In [14], the lumped elements are used to realize wideband response. However, lumped elements are limited in high-frequency applications, and the soldering will also involve undesirable parasitic effects. Instead of using lumped components, open/short stubs can be used to provide better high-frequency performance for the filtering ITs [16-20]. The equal-ripple response can be realized by lumped elements and J-inverters [24-27]. A Chebyshev polynomial is also used to constrain the equal-ripple response in filter and IT designs [28-30]. To realize DC block and reduce the circuit size, coupled line sections (CLSs) are widely used in wideband ITs and filters [31-45]. For example, two CLSs are added to each terminal of the stepped-impedance TLs symmetrically to integrate the filtering function [30].

To the best of the author's knowledge, there still are some relationships among these transformers and filters that are not mentioned. For example, in [26,28-30,33], filters and ITs with a Chebyshev response are constituted by cascaded CLSs and TLs. Although the similar design synthesis was reported, the numbers and positions of CLSs and TLs were not clear.

In this paper, a novel synthetization approach is presented for filter-integrated multisection wideband ITs. From the point of view of the number of variable parameters, the wideband IT, which consists of $N$ cascaded CLSs, is provided with a Chebyshev performance, where $N+2$ design conditions are consumed, and $N-2$ variable parameters remain. To further optimization, CLSs are newly substituted by TLs to consume the remaining variable parameters and simplify the circuit topology. Therefore, there are $2^{N}-N-2$ substituting possibilities in total for $N$-section ITs, and the design of the IT can be more flexible for both symmetric and asymmetric structures with the same wideband filtering performance.

\section{The Principle of the Synthetization Approach}

\subsection{The Number of Variable Parameters of Conventional N-Section IT}

Figure 2 shows the topology of $N$-section IT. It consists of $N$ cascaded CLSs with the electrical length $\theta$, where $Z_{\text {evi }}$ and $Z_{\text {odi }}$ are the even-and odd-mode characteristic impedances of the $i$ th CLS, and $i=1,2, \ldots, N$. $Z_{S}$ and $Z_{L}$ are two different terminal loads, and its impedance ratio $k$ is defined as $k=Z_{S} / Z_{L}, Z_{L}=1$ is defined in this paper; thus, $k>1$.

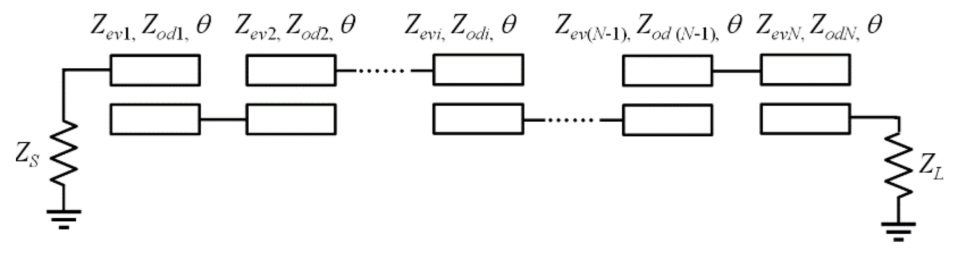

Figure 2. Topology of conventional $N$-section IT [28].

Based on [28], the $A B C D$ matrix of the $i$ th CLS can be summarized as

$$
\left[\begin{array}{cc}
A_{i} & B_{i} \\
C_{i} & D_{i}
\end{array}\right]=\frac{\sin \theta}{T_{i}}\left[\begin{array}{cc}
q S_{i} & \frac{j}{2} \\
2 j & {\left[T_{i}^{2}+q^{2}\left(T_{i}^{2}-S_{i}^{2}\right)\right]} \\
q S_{i}
\end{array}\right]
$$

where $q=\cot \theta$, and

$$
\begin{aligned}
& S_{i}=Z_{\text {evi }}+Z_{\text {odi }} \\
& T_{i}=Z_{\text {evi }}-Z_{\text {od } i}
\end{aligned}
$$


Then, the $A B C D$ matrix of $N$-section filter-integrated IT can be written as

$$
\left[\begin{array}{cc}
A_{T} & B_{T} \\
C_{T} & D_{T}
\end{array}\right]=\left[\begin{array}{cc}
A_{1} & B_{1} \\
C_{1} & D_{1}
\end{array}\right]\left[\begin{array}{cc}
A_{2} & B_{2} \\
C_{2} & D_{2}
\end{array}\right] \cdots\left[\begin{array}{cc}
A_{i} & B_{i} \\
C_{i} & D_{i}
\end{array}\right] \cdots\left[\begin{array}{cc}
A_{N-1} & B_{N-1} \\
C_{N-1} & D_{N-1}
\end{array}\right]\left[\begin{array}{cc}
A_{N} & B_{N} \\
C_{N} & D_{N}
\end{array}\right]
$$

where

$$
\begin{gathered}
A_{T}=\sum a_{p} \cos ^{p} \theta \\
B_{T}=\frac{j}{\sin \theta} \sum b_{q} \cos ^{q} \theta \\
C_{T}=\frac{j}{\sin \theta} \sum c_{q} \cos ^{q} \theta \\
D_{T}=\sum d_{p} \cos ^{p} \theta
\end{gathered}
$$

$a_{p}$ and $d_{p}$ are polynomial functions with degrees $p . b_{q}$ and $c_{q}$ are polynomial functions with degrees $q$. $p$ and $q$ defined in Equation (9). All polynomial functions can be determined by the even-and odd-mode characteristic impedances, respectively.

$$
\left\{\begin{array}{c}
p=1,3,5, \cdots, N q=0,2,4, \cdots, N+1 \text { when } N \text { is odd number } \\
p=0,2,4, \cdots, N q=1,3,5, \cdots, N+1 \text { when } N \text { is even number }
\end{array}\right.
$$

$S$-parameters of the $N$-section IT are

$$
\begin{aligned}
& S_{11}=\frac{A_{T} Z_{L}+B-C Z_{S} Z_{L}-D Z_{S}}{A_{T} Z_{L}+B+C Z_{S} Z_{L}+D Z_{S}} \\
& S_{21}=\frac{2 \sqrt{Z_{S} Z_{L}}}{A_{T} Z_{L}+B+C Z_{S} Z_{L}+D Z_{S}}
\end{aligned}
$$

The amplitude-squared transfer function can be expressed as

$$
\left|S_{21}^{\text {circuit }}(\theta)\right|^{2}=\frac{1}{1+\left|F_{\text {circuit }}\right|^{2}}=\frac{1}{1+\left|\left(A_{T}+B_{T}-k C_{T}-k D_{T}\right) / 2 \sqrt{k}\right|^{2}}
$$

where $F_{\text {circuit }}$ is the characteristic function of the circuit:

$$
F_{\text {circuit }}=\sum\left(a_{p}-k d_{p}\right) \cos ^{p} \theta / 2 \sqrt{k}+\frac{j}{\sin \theta} \sum\left(b_{q}-k c_{q}\right) \cos ^{q} \theta / 2 \sqrt{k}
$$

Conversely, based on the synthesis approach in [46], firstly, we define two variables: $x=\cos \phi=\alpha \cos \theta=\cos \theta / \cos \theta_{c}, y=\cos \xi=x \sin \theta_{c} / \sin \theta$, where $\theta_{c}$ is the electrical length at the lower cutoff frequency fc of the passband, and $\alpha$ is a quantity used to determine the bandwidth of a bandpass filter. The Chebyshev transfer function can be written as

$$
\left|S_{21}^{\text {formula }}(\theta)\right|^{2}=\frac{1}{1+\left|F_{\text {formula }}\right|^{2}}=\frac{1}{1+\varepsilon^{2} \cos ^{2}(N \phi+\xi)}
$$

where $\varepsilon=\sqrt{10^{0.1 L_{A}-1}}$, and $L_{A}$ is the in-band ripple level factor.

The characteristic function of Chebyshev formula $F_{\text {formula }}$ can be rewritten as:

$$
F_{\text {formula }}=\varepsilon \frac{\sum u_{q} \cos ^{q} \theta}{\sin \theta}
$$

From $F_{\text {circuit }}=F_{\text {formula }}$, the general design conditions of $N$-section IT are summarized as

$$
\left\{\begin{array}{c}
a_{p}-k d_{p}=0 \\
\left(b_{q}-k c_{q}\right) / 2 \sqrt{k}=\varepsilon u_{q}
\end{array}\right.
$$


Therefore, there are $2 \mathrm{~N}$ parameters of characteristic impedances in the $N$-section IT, where $N+2$ design conditions are used to derive the Chebyshev response in Equation (16), and $N-2$ variable parameters can be designated arbitrarily.

\subsection{The Proposed Synthesization Approach for Simplification}

To simplify the conventional topology [28] and decrease the number of extra variable parameters, TLs were used to substitute CLSs in this paper.

In Figure 3 , the $i$ th CLS is substituted by a single TL for example, where $Z_{i}$ and $\theta$ are the characteristic impedance and electrical length of the single TL. $Z_{\text {evi }}=2 Z_{i}$ and $Z_{\text {odi }}=0$ must be maintained. Then, the $A B C D$ matrix of TL can be rewritten as

$$
\left[\begin{array}{cc}
A_{i} & B_{i} \\
C_{i} & D_{i}
\end{array}\right]=\left[\begin{array}{cc}
\cos \theta & j \sin \theta Z_{e v i} / 2 \\
2 j \sin \theta / Z_{e v i} & \cos \theta
\end{array}\right]
$$

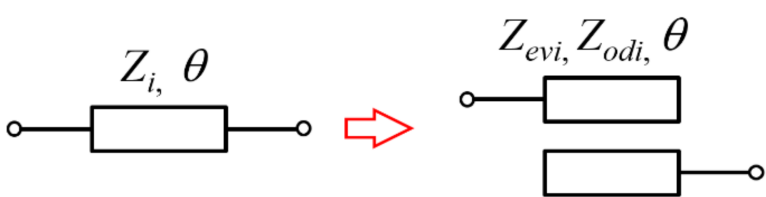

Figure 3. The $i$ th CLS is substituted by a single TL.

The $A B C D$ matrix form of the total topology will not be changed. In other words, when any single CLS ( $i$ th CLS) can be substituted by a single TL, Equation (4) can also be derived, and the characteristic impedances in all polynomial functions $\left(a_{p}, b_{p}, c_{p}\right.$ and $d_{p}$ ) will be slightly different because of $Z_{\text {evi }}=2 Z_{i}$ and $Z_{\text {odi }}=0$. Meanwhile, one variable parameter will be consumed, and the number of variable parameters will decrease to $N-3$. Furthermore, the consumption of more variable parameters, different positions, and more CLSs can be substituted by TLs, where the maximum number of substituted TLs is no more than $N-2$.

Based on the discussion above, the general procedure of the proposed synthetization approach in Figure 4 is summarized as follows: (1) according to the actual requirements, determine the section number $N$ in the conventional IT; (2) determine the number of CLSs needing to be substituted; (3) select the substituting positions of the CLSs; (4) calculate the $A B C D$ matrix; (5) calculate all the characteristic impedances by the Chebyshev response; (6) if the results cannot meet the design requirements, go back to (2) and re-design the circuit.

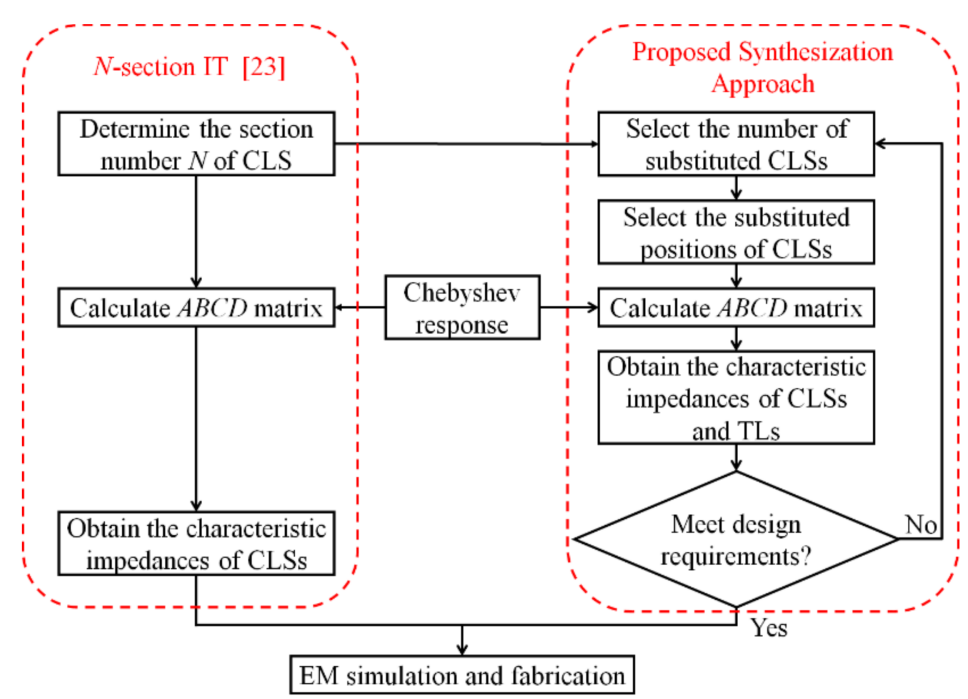

Figure 4. The proposed synthetization approach for $N$-section IT. 
In summary, for $N$-section IT $(N \geq 2)$ in Figure 2, the basic principle of substituting TL for CLS is summarized as follows:

(I) There are $2 N$ parameters in the $N$-section IT [28];

(II) $N+2$ design conditions are used to derive the Chebyshev response; thus, $N-2$ variable parameters can be designated arbitrarily;

(III) Consuming one variable parameter, a single TL could substitute one CLS to maintain the Chebyshev response. In other words, maximum number of TLs will reach to $N-2$;

(IV) After running through all the positions of substituted TLs in every possible combination, the number of the substitutable cases are listed in Table 1, and the total number is:

$$
C_{N}^{1}+C_{N}^{2}+\ldots+C_{N}^{N-2}=2^{N}-N-2
$$

Table 1. The number of substitutable cases for $N$-section IT.

\begin{tabular}{cc}
\hline Number of Substituted CLSs by TLs & Number of Substitutable Combinations \\
\hline 1 & $C_{N}^{1}$ \\
2 & $C_{N}^{2}$ \\
$\cdots$ & $\ldots$ \\
$N-3$ & $C_{N}^{N-3}$ \\
$N-2$ & $C_{N}^{N-2}$ \\
\hline
\end{tabular}

\section{Design Examples for the Proposed Synthetization Approach}

Several substituting cases have been discussed in previous works $(N=4)[28,30]$. To demonstrate the proposed synthetization approach, $N=5$ was selected to design the $N$-section IT. By using the proposed synthetization approach for simplification, there were 25 cases in total. All the cases are listed and compared in this section. In order words, refs. [28] and [30] are two cases in the proposed synthetization approach; the former have not yet been reported.

\subsection{Design Example for the Conventional 5-Section IT}

The topology of 5-section IT is shown in Figure 5. From Equation (4), $A_{T}, B_{T}, C_{T}$ and $D_{T}$ can be calculated as follows:

$$
\begin{gathered}
A_{T}=a_{5} \cos ^{5} \theta+a_{3} \cos ^{3} \theta+a_{1} \cos \theta \\
B_{T}=\frac{j}{\sin \theta}\left(b_{6} \cos ^{6} \theta+b_{4} \cos ^{4} \theta+b_{2} \cos ^{2} \theta+b_{0}\right) \\
C_{T}=\frac{j}{\sin \theta}\left(c_{6} \cos ^{6} \theta+c_{4} \cos ^{4} \theta+c_{2} \cos ^{2} \theta+c_{0}\right) \\
D_{T}=d_{5} \cos ^{5} \theta+d_{3} \cos ^{3} \theta+d_{1} \cos \theta
\end{gathered}
$$

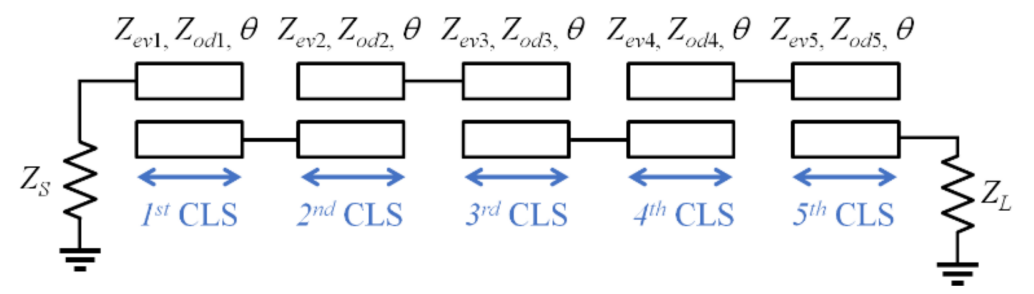

Figure 5. Topology of $N$-section IT [28] under the condition of $N=5$.

$a_{p}, d_{p}(p=1,3,5), b_{q}$ and $c_{q}(q=0,2,4,6)$ are the coefficients of the polynomial functions which are determined by characteristic impedances of $Z_{e v 1}, Z_{\text {od } 1}, Z_{e v 2}, Z_{\text {od } 2}, Z_{e v 3}, Z_{\text {od } 3}, Z_{e v 4}$, $Z_{o d 4}, Z_{e v 5}$ and $Z_{o d 5}$ (the detailed equations are listed in Table A1 in Appendix A). 
After the complicated arithmetical operation from Equations (10) to (13), $F_{\text {circuit }}$ can be written as

$$
\begin{aligned}
F_{\text {circuit }} & =\frac{1}{T_{1} T_{2} T_{3} T_{4} T_{5}}\left(X_{5} \cos ^{5} \theta+X_{3} \cos ^{3} \theta+X_{1} \cos \theta\right) \\
& +\frac{j}{T_{1} T_{2} T_{3} T_{4} T_{5} \sin \theta}\left(Y_{6} \cos ^{6} \theta+Y_{4} \cos ^{4} \theta+Y_{2} \cos ^{2} \theta+Y_{0}\right)
\end{aligned}
$$

where

$$
\begin{aligned}
& X_{p}=\left(a_{p}-k \cdot d_{p}\right) / 2 \sqrt{k} \\
& Y_{q}=\left(b_{q}-k \cdot c_{q}\right) / 2 \sqrt{k}
\end{aligned}
$$

Similarly, from Equations (10) to (13), $F_{\text {formula }}$ can be written as

$$
F_{\text {formula }}=\varepsilon \cos (5 \varphi+\xi)=\frac{\varepsilon}{\sin \theta}\left[u_{6} \cos ^{6} \theta+u_{4} \cos ^{4} \theta+u_{2} \cos ^{2} \theta+u_{0}\right]
$$

where

$$
\begin{gathered}
u_{6}=\frac{16}{\cos ^{6} \theta_{c}}\left(1+\sqrt{1-\cos ^{2} \theta_{c}}\right) \\
u_{4}=-\frac{4}{\cos ^{4} \theta_{c}}\left(5+7 \sqrt{1-\cos ^{2} \theta_{c}}\right) \\
u_{2}=\frac{1}{\cos ^{2} \theta_{c}}\left(5+13 \sqrt{1-\cos ^{2} \theta_{c}}\right) \\
u_{0}=-1
\end{gathered}
$$

From $F_{\text {circuit }}=F_{\text {formula }}$, the seven design conditions can be summarized as follows to maintain the Chebyshev response.

$$
\left\{\begin{array} { l } 
{ a _ { 5 } - k \cdot d _ { 5 } = 0 } \\
{ a _ { 3 } - k \cdot d _ { 3 } = 0 } \\
{ a _ { 1 } - k \cdot d _ { 1 } = 0 }
\end{array} \text { and } \left\{\begin{array}{l}
\left(b_{6}-k \cdot c_{6}\right) / 2 \sqrt{k}=\varepsilon u_{6} \\
\left(b_{4}-k \cdot c_{4}\right) / 2 \sqrt{k}=\varepsilon u_{4} \\
\left(b_{2}-k \cdot c_{2}\right) / 2 \sqrt{k}=\varepsilon u_{2} \\
\left(b_{0}-k \cdot c_{0}\right) / 2 \sqrt{k}=\varepsilon u_{0}
\end{array}\right.\right.
$$

For the section number $N=5$, there are 10 parameters $\left(Z_{e v 1}, Z_{o d 1}, Z_{e v 2}, Z_{o d 2}, Z_{e v 3}\right.$, $Z_{o d 3}, Z_{e v 4}, Z_{o d 4}, Z_{e v 5}$ and $Z_{o d 5}$ ) corresponding to seven design conditions for the Chebyshev response; thus, three variable parameters can be utilized to simplify the circuit topology.

\subsection{Design Example for Proposed Synthesization Approach}

Since there were 3 variable parameters, different 25 cases could be divided into three categories, Categories I, II and III, which will be discussed in this section.

\subsubsection{Category I: One CLS Is Substituted by TL}

When one CLS is substituted by TL, there are two variable parameters, and the number of the substitutable cases is $C_{5}^{1}=5$. Any of the CLSs (first, second, third, fourth, fifth) can be substituted by TL. All the possible cases are listed in Table 2. This is the simplest category; therefore, the detailed discussion will be omitted.

Table 2. The substitutable cases in category I.

\begin{tabular}{cccccc}
\hline The $i$ th CLS Substituted By TL & 1st & 2nd & 3rd & 4th & 5th \\
\hline Index of cases & Case 1 & Case 2 & Case 3 & Case 4 & Case 5 \\
\hline
\end{tabular}

\subsubsection{Category II: Two CLSs Are Substituted by TL}

When two CLSs are substituted by TLs, there is only one variable parameter left. The number of substitutable cases is $C_{5}^{2}=10$, and all the cases are listed in Table 3 . Case 11 is selected as an example and discussed in detail. The topology of case 11 is shown in 
Figure 6. For fabrication convenience, the odd-mode characteristic impedance of the third CLS is fixed to $0.6 \Omega\left(Z_{\text {od } 3}=0.6 \Omega\right)$. Since the second and fourth CLSs are substituted by TLs, $Z_{e v 2}=2 Z_{2}, Z_{o d 2}=0$ and $Z_{e v 4}=2 Z_{4}, Z_{o d 4}=0$ can be derived.

Table 3. The substitutable cases in category II.

\begin{tabular}{lllllll}
\hline & \multicolumn{5}{c}{ The $i$ th CLS Is Substituted by TL } \\
\hline & & 1st & 2nd & 3rd & 4th & 5th \\
\cline { 2 - 7 } & 1st & Case 6 & Case 7 & Case 8 & Case 9 \\
\cline { 2 - 7 } & 2nd & & Case 10 & Case 11 & Case 12 \\
\cline { 2 - 7 } & 3rd & & & Case 13 & Case 14 \\
\cline { 2 - 7 } & 4th & & & & Case 15 \\
\hline
\end{tabular}

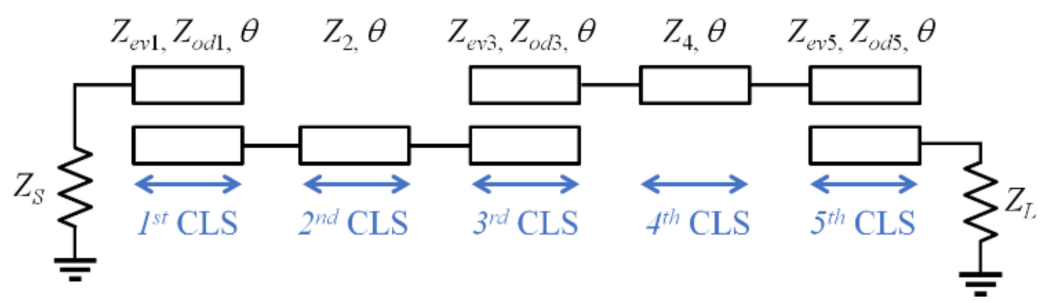

Figure 6. The topology of case 11 in category II.

Then, the relationship among the characteristic impedances of CLSs $\left(Z_{\text {evi }}\right.$ and $\left.Z_{\text {odi }}\right)$ and TLs $\left(Z_{i}\right)$, impedance ratio $k$ (where $1.5<k<5.0$ ), and electrical length $\theta_{c}$ (where $30^{\circ}<\theta_{c}<60^{\circ}$ ) are shown in Figure 7. As $k$ increase and $\theta_{c}$ decrease, the coupling strengths $C_{i}$ of all CLSs will become stronger, where $C_{i}=-20 \log \left(Z_{\text {evi }}-Z_{\text {odi }}\right) /\left(Z_{\text {evi }}+Z_{\text {odi }}\right), i=1$, 3 , and 5 . Therefore, the sum of all coupling strengths, $C_{\Sigma}$, will become smaller, where $C_{\Sigma}=C_{1}+C_{3}+C_{5}$, and the availability section is about $1.5<k<3.5$ and $30^{\circ}<\theta_{c}<60^{\circ}$
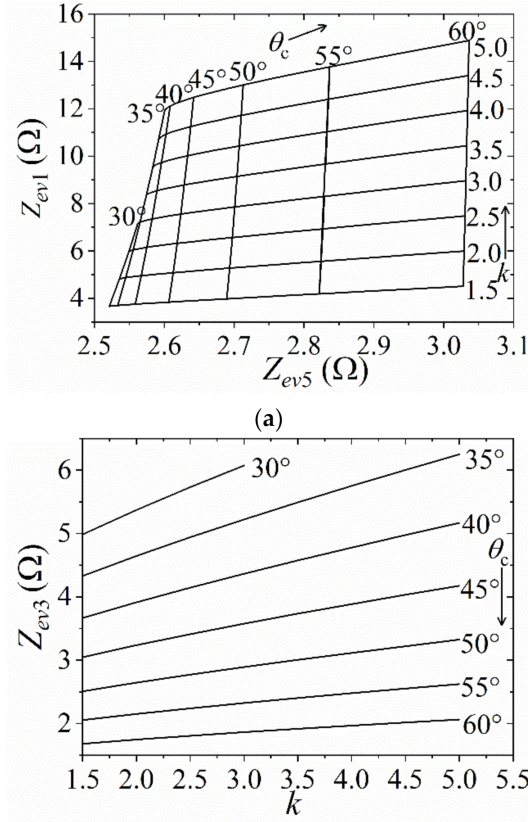

(c)

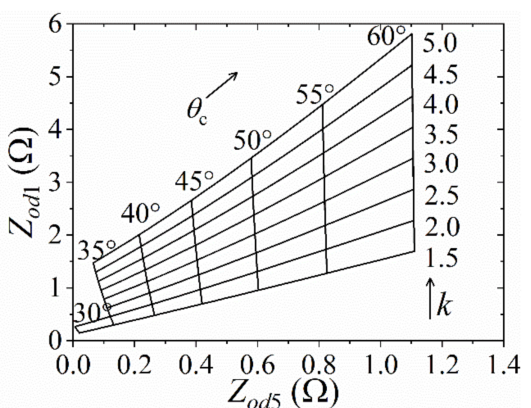

(b)

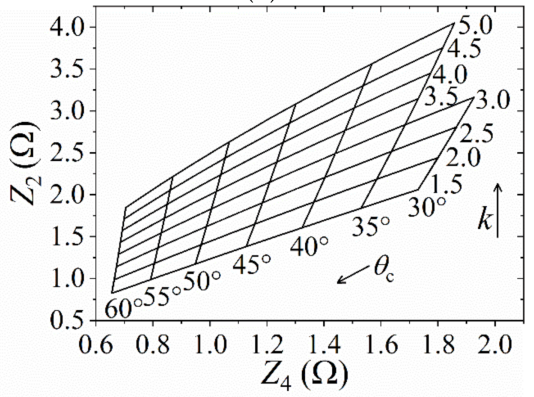

(d)

Figure 7. Relationships among characteristic impedance, $k$ and $\theta_{c}$ of case 11 under the condition of $R L=20 \mathrm{~dB}$. (a) Relationships about $Z_{e v 1}$ and $Z_{e v 5}$. (b) Relationships about $Z_{o d 1}$ and $Z_{o d 5}$. (c) Relationships about $Z_{e v 3}$ and $k$. (d) Relationships about $Z_{2}$ and $Z_{4}$. 


\subsubsection{Category III: Three CLSs Are Substituted by TL}

When three CLSs are substituted by TLs, there is no variable parameter. The number of substitutable cases is $C_{5}^{3}=10$, and all the cases are listed in Table 4. Case 21 is selected as an example and discussed in detail. The topology of case 21 is shown in Figure 8. Since the first, third, and fifth CLSs are substituted by TLs, $Z_{e v 1}=2 Z_{1}, Z_{o d 1}=0 ; Z_{e v 3}=2 Z_{3}, Z_{o d 3}=0$; and $Z_{e v 5}=2 Z_{5}, Z_{o d 5}=0$ can be derived.

Table 4. The substitutable cases of category III.

\begin{tabular}{|c|c|c|c|c|c|c|}
\hline \multirow{7}{*}{ 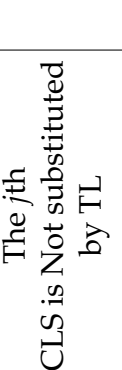 } & \multicolumn{6}{|c|}{ The ith CLS Is Not Substituted by TL } \\
\hline & & 1 st & 2nd & 3rd & 4th & 5 th \\
\hline & 1 st & & Case 16 & Case 17 & Case 18 & Case 19 \\
\hline & 2nd & & & Case 20 & Case 21 & Case 22 \\
\hline & $3 r d$ & & & & Case 23 & Case 24 \\
\hline & 4th & & & & & Case 25 \\
\hline & 5 th & & & & & \\
\hline
\end{tabular}

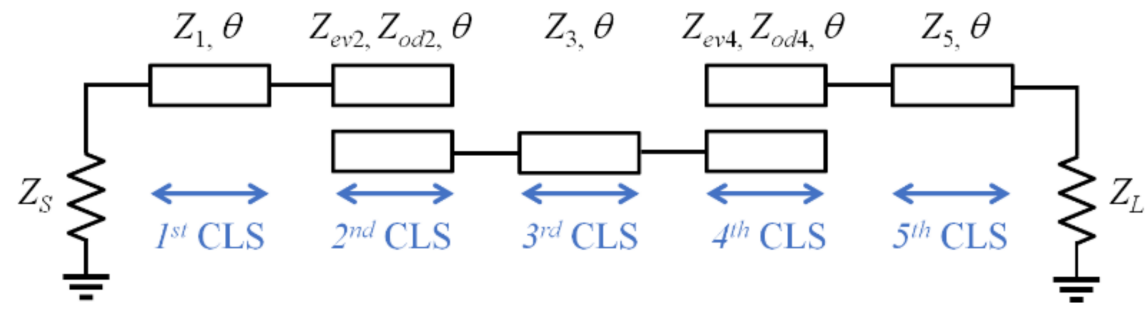

Figure 8. The topology of case 21 in category III.

The relationships among characteristic impedances of CLSs $\left(Z_{\text {evi }}\right.$ and $\left.Z_{\text {odi }}\right)$ and TLs $\left(Z_{i}\right)$, impedance ratio $k$ (where $1.5<k<5.0$ ), and electrical length $\theta_{c}$ (where $30^{\circ}<\theta_{c}<60^{\circ}$ ) are shown in Figure 9. The same results can be summarized accordingly: as $k$ increases and $\theta_{c}$ decreases, the coupling strengths $C_{2}$ and $C_{4}$ will become stronger, and $C_{\Sigma}$ will become smaller, where $C_{\Sigma}=C_{2}+C_{4}$. The first, third, and fifth CLSs are substituted by TLs; therefore, the availability section is narrower than case 11 , which is about $1.5<k<2.0$ and $30^{\circ}<\theta_{c}<35^{\circ}$.

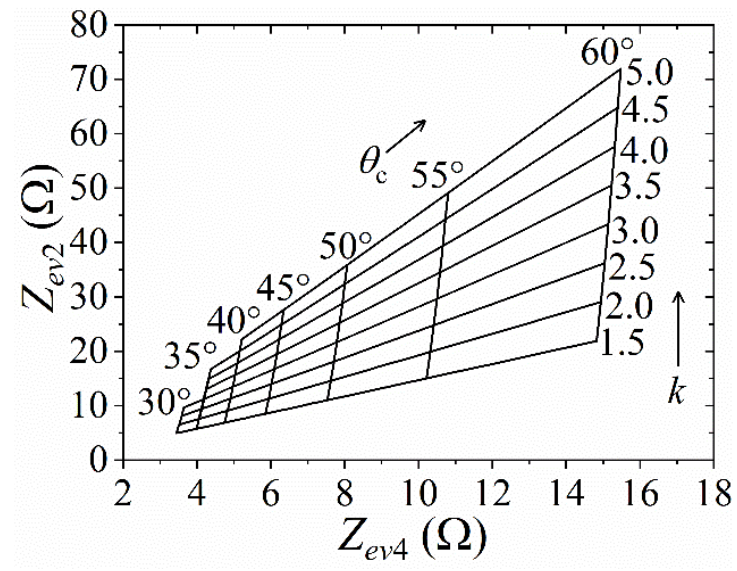

(a)

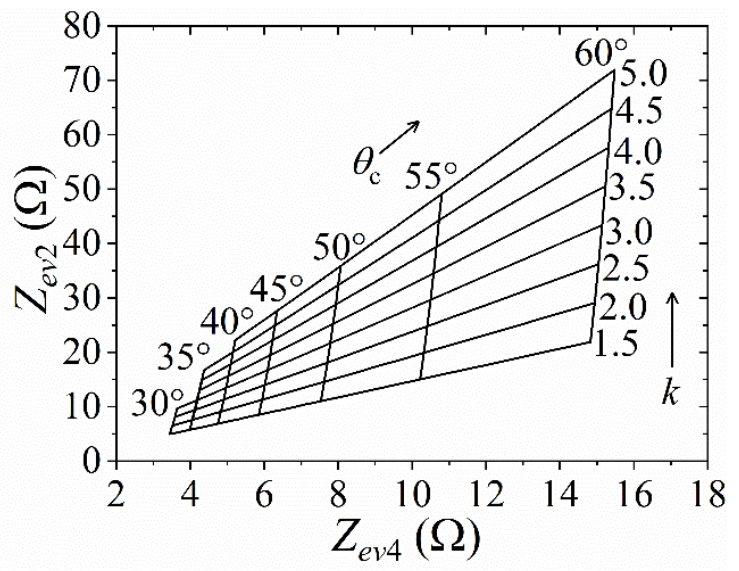

(b)

Figure 9. Cont. 


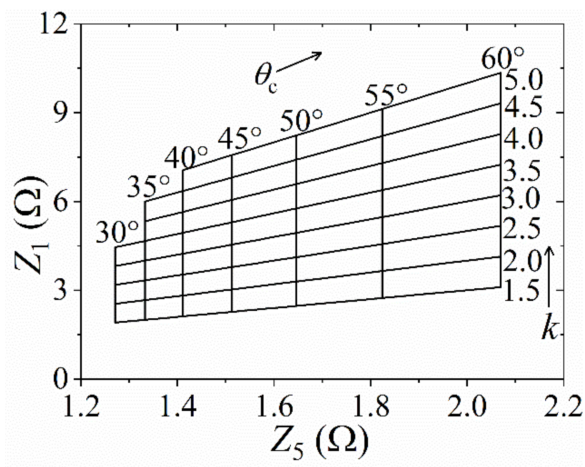

(c)

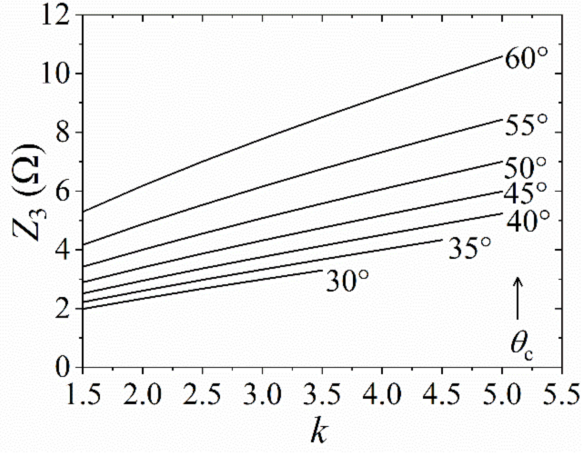

(d)

Figure 9. Relationships among characteristic impedance, $k$ and $\theta_{c}$ of case 21 under the condition of $R L=20 \mathrm{~dB}$. (a) Relationships about $Z_{e v 2}$ and $Z_{e v 4}$. (b) Relationships about $Z_{\text {od } 2}$ and $Z_{\text {od4 }}$. (c) Relationships about $Z_{1}$ and $Z_{5}$. (d) Relationships about $Z_{3}$ and $k$.

\subsection{Comparison and Summary}

To compare these three categories, seven selected examples are listed in Table 5 under the same design conditions $\left(\theta=90^{\circ}\right.$ at $f_{0}=2 \mathrm{GHz}, k=1.5, \theta_{c}=45^{\circ}$ and $\left.R L=20 \mathrm{~dB}\right)$. Their circuit simulation results are shown in Figure 10. The following conclusions are clearly summarized as:

Table 5. Typical simplification examples with detailed parameters, under the condition of $Z_{S}=1.5 \Omega$, $Z_{L}=1.0 \Omega, k=1.5, \theta=90$ at $f_{0}=2 \mathrm{GHz}, \theta_{\mathcal{C}}=45^{\circ}, R L=20 \mathrm{~dB}$.

\begin{tabular}{|c|c|c|c|c|c|c|c|}
\hline \multirow{2}{*}{$\begin{array}{l}\text { Number of } \\
\text { Variable } \\
\text { Parameters }\end{array}$} & \multirow{2}{*}{$\begin{array}{l}\text { Substitutable } \\
\text { Cases }\end{array}$} & \multicolumn{5}{|c|}{ Characteristic Impedances of the $i$ th CLSs or TLs $(\Omega)$} & \multirow{2}{*}{$\begin{array}{c}\text { Symmetrical/ } \\
\text { Asymmetrical } \\
\text { Topology }\end{array}$} \\
\hline & & 1st & 2nd & 3 rd & 4th & 5th & \\
\hline 3 & $\begin{array}{l}\text { Conventional } \\
\text { topology [28] } \\
\text { Former work }\end{array}$ & $\begin{array}{c}\text { CLS } \\
Z_{e v 1}=4.1030 \\
Z_{o d 1}=0.4371\end{array}$ & $\begin{array}{c}\text { CLS } \\
Z_{e v 2}=4.7546 \\
Z_{o d 2}=0.6000 \\
\end{array}$ & $\begin{array}{c}\text { CLS } \\
Z_{e v 3}=4.7474 \\
Z_{o d 3}=0.6000\end{array}$ & $\begin{array}{c}\text { CLS } \\
Z_{\text {ev4 }}=4.2000 \\
Z_{o d 4}=0.6000\end{array}$ & $\begin{array}{c}\text { CLS } \\
Z_{\text {ev5 }}=2.8441 \\
Z_{\text {od5 }}=0.1826\end{array}$ & Symmetrical \\
\hline 2 & $\begin{array}{c}\text { Case } 2 \\
\text { This work }\end{array}$ & $\begin{array}{c}\text { CLS } \\
Z_{e v 1}=3.8756 \\
Z_{o d 1}=0.6643\end{array}$ & $\begin{array}{c}\mathrm{TL} \\
\mathrm{Z}_{2}=1.5268\end{array}$ & $\begin{array}{c}\text { CLS } \\
Z_{e v 3}=3.8798 \\
Z_{o d 3}=0.6643\end{array}$ & $\begin{array}{c}\text { CLS } \\
Z_{e v 4}=3.9323 \\
Z_{o d 4}=0.6000\end{array}$ & $\begin{array}{c}\text { CLS } \\
Z_{e v 5}=2.8214 \\
Z_{o d 5}=0.2053 \\
\end{array}$ & Asymmetrical \\
\hline \multirow{2}{*}{1} & $\begin{array}{l}\text { Case } 11 \\
\text { in Figure } 5 \\
\text { This work }\end{array}$ & $\begin{array}{c}\text { CLS } \\
Z_{e v 1}=3.8447 \\
Z_{o d 1}=0.6953\end{array}$ & $\begin{array}{c}\mathrm{TL} \\
Z_{2}=1.4813\end{array}$ & $\begin{array}{c}\text { CLS } \\
Z_{e v 3}=3.0487 \\
Z_{o d 3}=0.6000\end{array}$ & $\begin{array}{c}\mathrm{TL} \\
\mathrm{Z}_{4}=1.1271\end{array}$ & $\begin{array}{c}\text { CLS } \\
Z_{e v 5}=2.6067 \\
Z_{o d 5}=0.4200\end{array}$ & Symmetrical \\
\hline & $\begin{array}{l}\text { Case } 10 \\
\text { This work }\end{array}$ & $\begin{array}{c}\text { CLS } \\
Z_{e v 1}=3.7642 \\
Z_{o d 1}=0.7758\end{array}$ & $\begin{array}{c}\mathrm{TL} \\
\mathrm{Z}_{2}=1.1076\end{array}$ & $\begin{array}{c}\mathrm{TL} \\
\mathrm{Z}_{3}=0.9148\end{array}$ & $\begin{array}{c}\text { CLS } \\
Z_{e v 4}=3.0366 \\
Z_{o d 4}=0.6000\end{array}$ & $\begin{array}{c}\text { CLS } \\
Z_{\text {ev5 }}=2.7415 \\
Z_{o d 5}=0.2852 \\
\end{array}$ & Asymmetrical \\
\hline \multirow{3}{*}{0} & $\begin{array}{l}\text { Case } 18 \\
\text { This work }\end{array}$ & $\begin{array}{c}\text { CLS } \\
Z_{e v 1}=3.8158 \\
Z_{o d 1}=0.7242\end{array}$ & $\begin{array}{c}\mathrm{TL} \\
\mathrm{Z}_{2}=1.2486\end{array}$ & $\begin{array}{c}\mathrm{TL} \\
Z_{3}=1.4696\end{array}$ & $\begin{array}{c}\text { CLS } \\
Z_{e v 4}=5.5788 \\
Z_{o d 4}=1.5118\end{array}$ & $\begin{array}{c}\mathrm{TL} \\
Z_{5}=1.5133\end{array}$ & Asymmetrical \\
\hline & $\begin{array}{c}\text { Case } 19[30] \\
\text { Former work }\end{array}$ & $\begin{array}{c}\text { CLS } \\
Z_{e v 1}=3.7113 \\
Z_{o d 1}=0.8287\end{array}$ & $\begin{array}{c}\mathrm{TL} \\
\mathrm{Z}_{2}=0.7888\end{array}$ & $\begin{array}{c}\mathrm{TL} \\
Z_{3}=0.4592\end{array}$ & $\begin{array}{c}\mathrm{TL} \\
\mathrm{Z}_{4}=0.6071\end{array}$ & $\begin{array}{c}\text { CLS } \\
Z_{e v 5}=2.4931 \\
Z_{o d 5}=0.5336\end{array}$ & Symmetrical \\
\hline & $\begin{array}{l}\text { Case } 21 \\
\text { in Figure } 7 \\
\text { This work }\end{array}$ & $\begin{array}{c}\mathrm{TL} \\
Z_{1}=2.2700\end{array}$ & $\begin{array}{c}\text { CLS } \\
Z_{e v 2}=8.5051 \\
Z_{o d 2}=2.1307\end{array}$ & $\begin{array}{c}\mathrm{TL} \\
Z_{3}=2.8948\end{array}$ & $\begin{array}{c}\text { CLS } \\
Z_{e v 4}=5.8497 \\
Z_{o d 4}=1.2408\end{array}$ & $\begin{array}{c}\mathrm{TL} \\
Z_{5}=1.5133\end{array}$ & Symmetrical \\
\hline
\end{tabular}




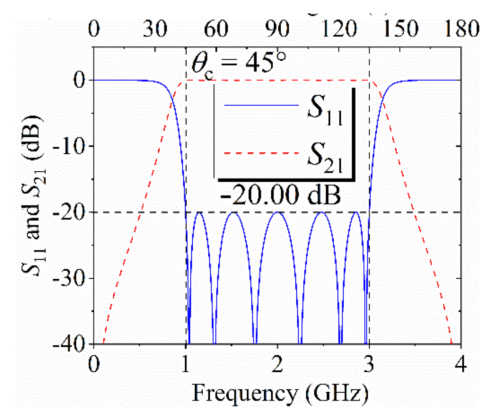

(a)

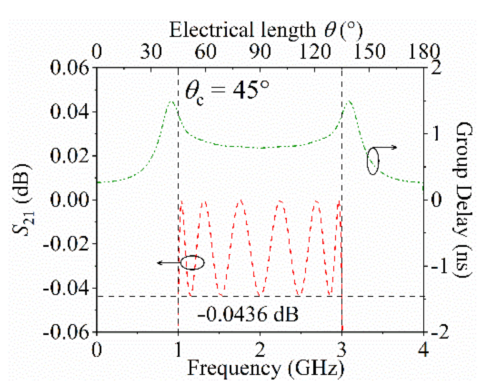

(b)

Figure 10. Circuit simulations of the 7 selected examples in Table 5. (a) Circuit simulations of $S_{11}$ and $S_{21}$. (b) Enlarged circuit simulations of $S_{21}$ and group delay.

(1) Although all the topologies (25 cases) are quite different, by using the proposed synthetization approach, the same Chebyshev frequency responses $\left(S_{11}, S_{21}\right.$ and group delay) can be derived.

(2) Symmetrical or asymmetrical topology will not affect the Chebyshev frequency responses, which are only determined by all the characteristic impedances of CLSs and TLs.

(3) When the category is determined, considering coupling strengths and impedance ratio, CLSs are preferred to connect the source and load terminals in symmetrical topology.

(4) More variable parameters will provide more flexible design procedures and wider realization ranges. When the number of variable parameters is zero, the most simplification topology appears with the unique solution of characteristic impedances. Although the realization range is quite limited, the circuit is highly convenient for fabrication.

\section{Experimental Results}

To validate the proposed synthetization approach, a $75 \Omega-50 \Omega$ IT (case 11) was designed, fabricated, and measured, where $\theta_{c}=45^{\circ}, \mathrm{RL}=20 \mathrm{~dB}$, and the center frequency $f_{0}=2 \mathrm{GHz}$. The characteristic impedances and the physical parameters of the fabricated IT are listed in Tables 6 and A1.

Table 6. Parameters of the fabricated IT.

\begin{tabular}{|c|c|c|}
\hline Characteristic Impedance $(\Omega)$ & Coupling Strength (dB) & Physical Parameters (mm) \\
\hline $\begin{array}{c}Z_{e v 1}=192.23 \\
Z_{o d 1}=34.77\end{array}$ & 3.18 & $\begin{array}{l}W_{1}=4.0 \\
L_{1}=27.5 \\
S_{1}=10.8\end{array}$ \\
\hline$Z_{2}=69.06$ & & $\begin{array}{l}W_{2}=1.4 \\
L_{2}=27.0\end{array}$ \\
\hline $\begin{array}{c}Z_{e v 3}=152.43 \\
Z_{o d 3}=30.00\end{array}$ & 3.46 & $\begin{array}{c}W_{3}=4.9 \\
L_{3}=26.7 \\
S_{3}=8.4\end{array}$ \\
\hline$Z_{4}=56.35$ & & $\begin{array}{l}W_{4}=2.1 \\
L_{4}=26.0\end{array}$ \\
\hline $\begin{array}{c}Z_{e v 5}=130.33 \\
Z_{o d 5}=20.10\end{array}$ & 2.82 & $\begin{array}{l}W_{5}=7.6 \\
L_{5}=26.4 \\
S_{5}=10.3\end{array}$ \\
\hline
\end{tabular}

The slot-coupled directional (SCD) structure was used in the circuit fabrication. The $3 \mathrm{D}$ view of the proposed IT is shown in Figure 11. The structure was constructed on the Roger's RT/duroid 5880 substrate with a dielectric constant $\left(\varepsilon_{r}\right)$ of 2.2, a loss tangent $(\tan \delta)$ of 0.0009 , and a thickness of $0.787 \mathrm{~mm}$. 

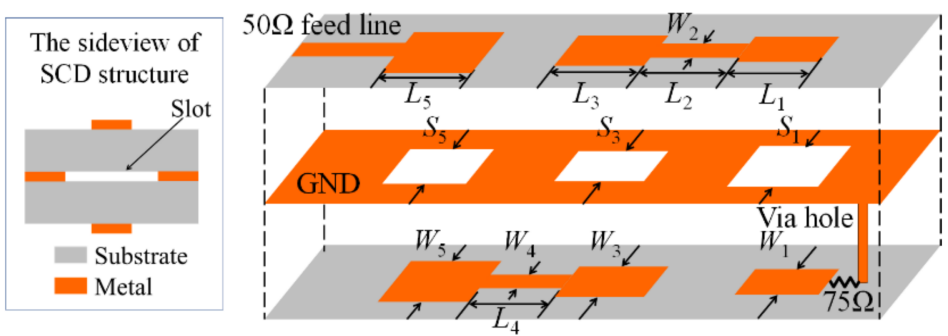

Figure 11. The 3D view of the proposed impedance transformer.

Figure 12a,b shows the front- and back-side photographs of the fabricated IT. Its circuit simulation, EM simulation, and measured results are shown in Figure 13. The $S_{11}$ of EM simulation and measured results were lower than $-17.1 \mathrm{~dB}$ and $-14.5 \mathrm{~dB}$ in the passband, respectively. The errors between the EM simulation and measured results were mainly caused by fabrication error and parasitic effect around the terminal $75 \Omega$ resistor. Four reflection zeros within the passband can clearly be observed in the measurement results.

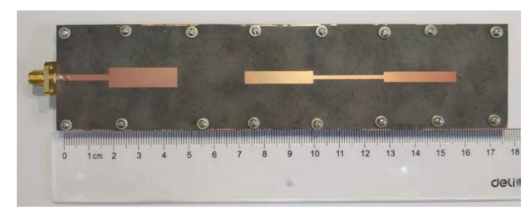

(a)

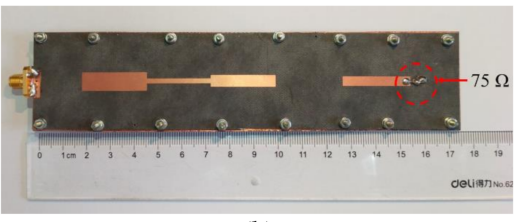

(b)

Figure 12. Photographs of the fabricated transformer. (a) Front-side view; (b) back-side view.

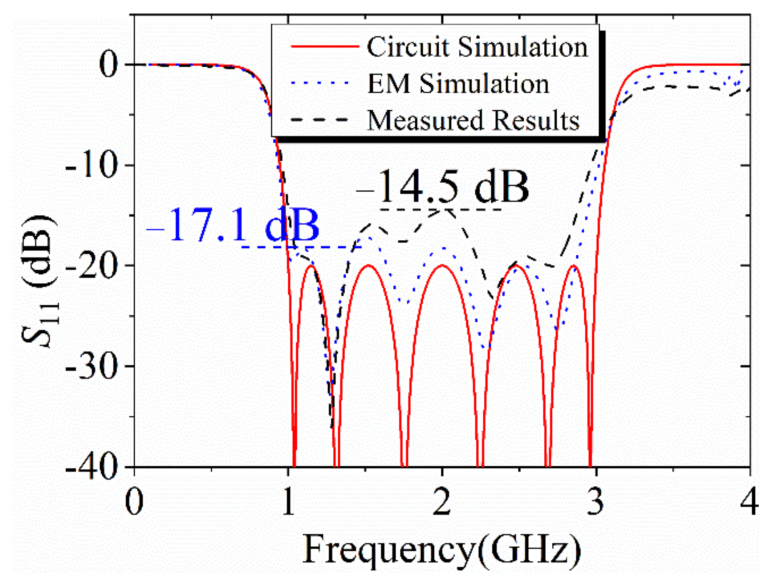

Figure 13. Circuit simulation, EM simulation and measured results.

\section{Conclusions}

In this paper, a novel synthetization approach for the $\mathrm{N}$-section IT has been proposed. Based on the principles of this proposed approach, TLs could substitute CLSs for flexible circuit design, simplified circuit topology, and easy fabrication; moreover, the same Chebyshev response will be maintained. Furthermore, through analyzing the relationship between the number of variable parameters and the number of design conditions, at most, $N-2$ CLSs can be substituted by TLs, and the substituting positions can be selected flexibly. Therefore, both symmetric and asymmetric substituting structures can be realized. To validate the proposed theory, a $75 \Omega-50 \Omega$ filtering IT was fabricated and measured. The measured results met the circuit simulation and the EM simulation effectively. This work has proposed a novel synthetization approach for IT design, and a detailed mathematical approach has been presented, which can be significant in IT and the design of other components. However, parts of the circuits were not easy to fabricate because of the strong coupled strength. In our future works, we will focus on changing the structure to decrease 
the coupled strength and provide extra transmission zeros to improve the selectivity of the IT.

Author Contributions: Conceptualization, N.Z., X.W., C.-P.C. and Z.M.; Data curation, N.Z.; Formal analysis, N.Z. and X.W.; Funding acquisition, X.W. and G.L.; Investigation, N.Z. and X.W.; Methodology, N.Z. and X.W.; Project administration, X.W. and G.L.; Resources, X.W. and G.L.; Software, N.Z.; Supervision, X.W. and G.L.; Validation, N.Z. and X.W.; Visualization, N.Z., X.W. and C.B.; Writing—original draft, N.Z., X.W. and B.W.; Writing-review and editing, N.Z. and X.W. All authors have read and agreed to the published version of the manuscript.

Funding: This work was funded by the National Natural Science Foundation of China (Grant No. 61701189), Project of the Education Department of Jilin Province (Grant No. JJKH20211093KJ), Interdisciplinary Integration and Innovation Project of JLU (Grant No. JLUXKJC2020204), "the Fundamental Research Funds for the Central Universities", the Project of Science and Technology Development Program (Grant No. 21ZY23) and Grand-in-Aid for Scientific Research from the Ministry of Education, Culture, Sports, Science and Technology (Grant No.16K06320), Japan.

Conflicts of Interest: The authors declare no conflict of interest.

\section{Appendix A}

For the 5-section IT [28], the detail parameters of $a_{p}, b_{q}, c_{q}$ and $d_{p}$ are summarized and listed in Table A1.

Table A1. Detailed parameter for the 5-section IT [28].

\begin{tabular}{|c|}
\hline $\begin{array}{c}a_{5}=\frac{1}{T_{1} T_{2} T_{3} T_{4} T_{5}}\left[S_{1}\left(S_{1}+S_{2}\right)\left(S_{2}+S_{3}\right)\left(S_{3}+S_{4}\right)\left(S_{4}+S_{5}\right)\right] \\
a_{3}=-\frac{1}{T_{1} T_{2} T_{3} T_{4} T_{5}}\left[\left(S_{2}+S_{3}\right)\left(S_{3}+S_{4}\right)\left(S_{4}+S_{5}\right) T_{1}^{2}+S_{1}\left(S_{3}+S_{4}\right)\left(S_{4}+S_{5}\right) T_{2}^{2}+S_{1}\left(S_{1}+S_{2}\right)\left(S_{4}+S_{5}\right) T_{3}^{2}+S_{1}\left(S_{1}+S_{2}\right)\left(S_{2}+S_{3}\right) T_{4}^{2}\right] \\
a_{1}=\frac{1}{T_{1} T_{2} T_{3} T_{4} T_{5}}\left[S_{1} T_{2}^{2} T_{4}^{2}+\left(S_{2}+S_{3}\right) T_{1}^{2} T_{4}^{2}+\left(S_{4}+S_{5}\right) T_{1}^{2} T_{3}^{2}\right]\end{array}$ \\
\hline $\begin{array}{c}b_{6}=-\frac{1}{2 T_{1} T_{2} T_{3} T_{4} T_{5}}\left[S_{1} S_{5}\left(S_{1}+S_{2}\right)\left(S_{2}+S_{3}\right)\left(S_{3}+S_{4}\right)\left(S_{4}+S_{5}\right)\right] \\
b_{4}=\frac{1}{2 T_{1} T_{2} T_{3} T_{4} T_{5}}\left[S_{5}\left(S_{2}+S_{3}\right)\left(S_{3}+S_{4}\right)\left(S_{4}+S_{5}\right) T_{1}^{2}+S_{1} S_{5}\left(S_{3}+S_{4}\right)\left(S_{4}+S_{5}\right) T_{2}^{2}+S_{1} S_{5}\left(S_{1}+S_{2}\right)\left(S_{4}+S_{5}\right) T_{3}^{2}+S_{1} S_{5}\left(S_{1}+S_{2}\right)\left(S_{2}+S_{3}\right) T_{4}^{2}\right. \\
\left.+S_{1}\left(S_{1}+S_{2}\right)\left(S_{2}+S_{3}\right)\left(S_{3}+S_{4}\right) T_{5}^{2}\right] \\
b_{2}=-\frac{1}{2 T_{1} T_{2} T_{3} T_{4} T_{5}}\left[\left(S_{2}+S_{3}\right)\left(S_{3}+S_{4}\right) T_{1}^{2} T_{5}^{2}+S_{5}\left(S_{4}+S_{5}\right) T_{1}^{2} T_{3}^{2}+S_{5}\left(S_{2}+S_{3}\right) T_{1}^{2} T_{4}^{2}+S_{1}\left(S_{1}+S_{2}\right) T_{3}^{2} T_{5}^{2}+S_{1}\left(S_{3}+S_{4}\right) T_{2}^{2} T_{5}^{2}+S_{1} S_{5} T_{2}^{2} T_{4}^{2}\right] \\
b_{0}=\frac{T_{1} T_{3} T_{5}}{2 T_{2} T_{4}}\end{array}$ \\
\hline $\begin{array}{c}c_{6}=-\frac{2}{T_{1} T_{2} T_{3} T_{4} T_{5}}\left(S_{1}+S_{2}\right)\left(S_{2}+S_{3}\right)\left(S_{3}+S_{4}\right)\left(S_{4}+S_{5}\right) \\
c_{4}=\frac{2}{T_{1} T_{2} T_{3} T_{4} T_{5}}\left\{\left(S_{1}+S_{2}\right)\left(S_{2}+S_{3}\right)\left(S_{3}+S_{4}\right)\left(S_{4}+S_{5}\right)+\left(S_{3}+S_{4}\right)\left(S_{4}+S_{5}\right) T_{2}^{2}+\left(S_{1}+S_{2}\right)\left(S_{4}+S_{5}\right) T_{3}^{2}+\left(S_{1}+S_{2}\right)\left(S_{2}+S_{3}\right) T_{4}^{2}\right\} \\
c_{2}=-\frac{2}{T_{1} T_{2} T_{3} T_{4} T_{5}}\left[\left(S_{3}+S_{4}\right)\left(S_{4}+S_{5}\right) T_{2}^{2}+\left(S_{1}+S_{2}\right)\left(S_{4}+S_{5}\right) T_{3}^{2}+\left(S_{1}+S_{2}\right)\left(S_{2}+S_{3}\right) T_{4}^{2}+T_{2}^{2} T_{4}^{2}\right] \\
c_{0}=\frac{2 T_{2} T_{4}}{T_{1} T_{3} T_{5}}\end{array}$ \\
\hline $\begin{array}{c}d_{5}=\frac{1}{T_{1} T_{2} T_{3} T_{4} T_{5}} S_{5}\left(S_{1}+S_{2}\right)\left(S_{2}+S_{3}\right)\left(S_{3}+S_{4}\right)\left(S_{4}+S_{5}\right) \\
d_{3}=-\frac{1}{T_{1} T_{2} T_{3} T_{4} T_{5}}\left[S_{5}\left(S_{3}+S_{4}\right)\left(S_{4}+S_{5}\right) T_{2}^{2}+S_{5}\left(S_{1}+S_{2}\right)\left(S_{4}+S_{5}\right) T_{3}^{2}+S_{5}\left(S_{1}+S_{2}\right)\left(S_{2}+S_{3}\right) T_{4}^{2}+\left(S_{1}+S_{2}\right)\left(S_{2}+S_{3}\right)\left(S_{3}+S_{4}\right) T_{5}^{2}\right] \\
d_{1}=\frac{1}{T_{1} T_{2} T_{3} T_{4} T_{5}}\left[S_{5} T_{2}^{2} T_{4}^{2}+\left(S_{1}+S_{2}\right) T_{3}^{2} T_{5}^{2}+\left(S_{3}+S_{4}\right) T_{2}^{2} T_{5}^{2}\right]\end{array}$ \\
\hline
\end{tabular}

\section{References}

1. Matthzei, G.L.; Young, L.; Jones, E.M.T. Microwave Filters, Impedance-Matching Networks and Coupling Structures; Artech House: Norwood, MA, USA, 1980.

2. Riblet, H. General Synthesis of Quarter-Wave Impedance Transformers. IEEE Trans. Microw. Theory Tech. 1957, 5, 36-43. [CrossRef]

3. Chow, Y.; Wan, K. A transformer of one-third wavelength in two sections-For a frequency and its first harmonic. IEEE Microw. Wirel. Compon. Lett. 2002, 12, 22-23. [CrossRef]

4. Monzon, C. Analytical derivation of a two-section impedance transformer for a frequency and its first harmonic. IEEE Microw. Wirel. Compon. Lett. 2002, 12, 381-382. [CrossRef]

5. Liu, X.; Liu, Y.; Li, S.; Wu, F.; Wu, Y. A Three-Section Dual-Band Transformer for Frequency-Dependent Complex Load Impedance. IEEE Microw. Wirel. Compon. Lett. 2009, 19, 611-613. [CrossRef]

6. Darraji, R.; Honari, M.M.; Mirzavand, R.; Ghannouchi, F.M.; Mousavi, P. Wideband Two-Section Impedance Transformer with Flat Real-to-Real Impedance Matching. IEEE Microw. Wirel. Compon. Lett. 2016, 26, 313-315. [CrossRef]

7. Liu, L.; Jin, R.; Liang, X.; Fan, H.; Wang, W.; Geng, J.; Liu, F.; Chen, Y. Multifrequency Transformer with Arbitrary Frequency and Real Impedance Transform Ratio. IEEE Microw. Wirel. Compon. Lett. 2017, 27, 1-3. [CrossRef] 
8. Chuang, M.-L. Dual-Band Impedance Transformer Using Two-Section Shunt Stubs. IEEE Trans. Microw. Theory Tech. 2010, 58, 1257-1263. [CrossRef]

9. Chuang, M.-L.; Wu, M.-T. Transmission Zero Embedded Dual-Band Impedance Transformer with Three Shunt Stubs. IEEE Microw. Wirel. Components Lett. 2017, 27, 788-790. [CrossRef]

10. Wu, Y.; Pan, L.; Wang, W.; Yang, Y.; Wei, Y.; Wu, H.; Ma, L. A New Self-Packaged Substrate Integrated Air-Filled Spoof Surface Plasmon Polaritons Line with Inherent Low Loss and Deep Upper Frequency Suppression. IEEE Trans. Plasma Sci. 2020, 48, 3516-3523. [CrossRef]

11. Pan, L.; Wu, Y.; Wang, W.; Wei, Y.; Yang, Y. A Flexible High-Selectivity Single-Layer Coplanar Waveguide Bandpass Filter Using Interdigital Spoof Surface Plasmon Polaritons of Bow-Tie Cells. IEEE Trans. Plasma Sci. 2020, 48, 3582-3588. [CrossRef]

12. Wei, Y.; Wu, Y.; Wang, W.; Pan, L.; Yang, Y.; Liu, Y. Double-Sided Spoof Surface Plasmon Polaritons- Line Bandpass Filter With Excellent Dual-Band Filtering and Wide Upper Band Suppressions. IEEE Trans. Plasma Sci. 2020, 48, 4134-4143. [CrossRef]

13. Chen, W.; Wu, Y.; Yang, Y.; Wang, W. IPD-Based Miniaturized Wideband Bandpass Filter with Frequency-Dependent Complex Source and Load. IEEE Trans. Plasma Sci. 2021, 49, 1115-1120. [CrossRef]

14. Zhang, R.; Luo, S.; Zhu, L. Synthesis and Design of Mixed Lumped and Distributed Low-Pass Filters/Low-Passing Impedance Transformers with Taylor Series. IEEE Trans. Microw. Theory Tech. 2016, 64, 1265-1272. [CrossRef]

15. Zhu, L.; Shi, H.; Menzel, W. Coupling behaviors of quarter-wavelength impedance transformers for wideband CPW bandpass filters. IEEE Microw. Wirel. Components Lett. 2005, 15, 13-15. [CrossRef]

16. Van Der Walt, P. Short-Step-Stub Chebyshev Transformers Impedance. IEEE Trans. Microw. Theory Tech. 1986, 34, 863-868. [CrossRef]

17. Chang, W.-S.; Chang, C.-Y. Analytical Design of Microstrip Short-Circuit Terminated Stepped-Impedance Resonator Dual-Band Filters. IEEE Trans. Microw. Theory Tech. 2011, 59, 1730-1739. [CrossRef]

18. Zhang, R.; Zhu, L. Design of a Wideband Bandpass Filter with Composite Short- and Open-Circuited Stubs. IEEE Microw. Wirel. Components Lett. 2013, 24, 96-98. [CrossRef]

19. Wu, Q.-S.; Zhu, L. Wideband Impedance Transformers with Good Frequency Selectivity Based on Multisection Quarter-Wave Lines and Short-Circuited Stubs. IEEE Microw. Wirel. Components Lett. 2016, 26, 337-339. [CrossRef]

20. Wang, X.; Ma, Z.; Xie, T.; Ohira, M.; Chen, C.-P.; Lu, G. Synthesis Theory of Ultra-Wideband Bandpass Transformer and its Wilkinson Power Divider Application with Perfect in-Band Reflection/Isolation. IEEE Trans. Microw. Theory Tech. 2019, 67, 3377-3390. [CrossRef]

21. Guo, L.; Zhu, H.; Abbosh, A. Planar UWB phase shifter using parallel coupled lines combined with short-ended stubs and impedance transformer. In Proceedings of the 2015 Asia-Pacific Microwave Conference (APMC), Nanjing, China, 6-9 December 2015; pp. 1-3. [CrossRef]

22. Kong, M.; Wu, Y.; Zhuang, Z.; Wang, W.; Wang, C. Ultraminiaturized Wideband Quasi-Chebyshev/-Elliptic ImpedanceTransforming Power Divider Based on Integrated Passive Device Technology. IEEE Trans. Plasma Sci. 2020, 48, 858-866. [CrossRef]

23. Rayno, J.; Celik, N.; Iskander, M.F. Dual-Polarization Cylindrical Long-Slot Array (CLSA) Antenna Integrated with Compact Broadband Baluns and Slot Impedance Transformers. IEEE Antennas Wirel. Propag. Lett. 2013, 12, 1384-1387. [CrossRef]

24. Gao, S.S.; Sun, S. Synthesis of Wideband Parallel-Coupled Line Bandpass Filters with Non-Equiripple Responses. IEEE Microw. Wirel. Components Lett. 2014, 24, 587-589. [CrossRef]

25. Orellana, M.; Selga, J.; Velez, P.; Sans, M.; Rodriguez, A.; Bonache, J.; Boria, V.E.; Martin, F. Design of Capacitively Loaded Coupled-Line Bandpass Filters with Compact Size and Spurious Suppression. IEEE Trans. Microw. Theory Tech. 2017, 65, 1235-1248. [CrossRef]

26. Park, J.-H.; Lee, S.; Lee, Y. Extremely Miniaturized Bandpass Filters Based on Asymmetric Coupled Lines with Equal Reactance. IEEE Trans. Microw. Theory Tech. 2011, 60, 261-269. [CrossRef]

27. Lee, S.; Lee, Y. Generalized Miniaturization Method for Coupled-Line Bandpass Filters by Reactive Loading. IEEE Trans. Microw. Theory Tech. 2010, 58, 2383-2391. [CrossRef]

28. Chin, K.-S.; Chiou, Y.-C.; Kuo, J.-T. New Synthesis of Parallel-Coupled Line Bandpass Filters with Chebyshev Responses. IEEE Trans. Microw. Theory Tech. 2008, 56, 1516-1523. [CrossRef]

29. Sun, S.; Zhu, L. Improved formulas for synthesizing multiple-mode-resonator-based UWB bandpass filters. In Proceedings of the 2009 European Microwave Conference (EuMC), Rome, Italy, 29 September-1 October 2009; pp. 299-302. [CrossRef]

30. Wu, Q.-S.; Zhu, L. Wideband Impedance Transformers on Parallel-Coupled and Multisection Microstrip Lines: Synthesis Design and Implementation. IEEE Trans. Components, Packag. Manuf. Technol. 2016, 6, 1873-1880. [CrossRef]

31. Ang, K.S.; Lee, C.H.; Leong, Y.C. Analysis and design of coupled line impedance transformers. In Proceedings of the 2004 IEEE MTT-S International Microwave Symposium Digest (IEEE Cat. No.04CH37535), Fort Worth, TX, USA, 6-11 June 2004; Volume 3, pp. 1951-1954. [CrossRef]

32. Cheong, P.; Fok, S.-W.; Tam, K.W. Miniaturized parallel coupled-line bandpass filter with spurious-response suppression. IEEE Trans. Microw. Theory Tech. 2005, 53, 1810-1816. [CrossRef]

33. Chin, K.-S.; Kuo, J.-T. Insertion loss function synthesis of maximally flat parallel-coupled line bandpass filters. IEEE Trans. Microw. Theory Tech. 2005, 53, 3161-3168. [CrossRef]

34. Zhu, L.; Sun, S.; Menzel, W. Ultra-wideband (UWB) bandpass filters using multiple-mode resonator. IEEE Microw. Wirel. Components Lett. 2005, 15, 796-798. [CrossRef] 
35. Jensen, T.; Zhurbenko, V.; Krozer, V.; Meincke, P. Coupled Transmission Lines as Impedance Transformer. IEEE Trans. Microw. Theory Tech. 2007, 55, 2957-2965. [CrossRef]

36. Chen, M.-G.; Hou, T.-B.; Tang, C.-W. Design of Planar Complex Impedance Transformers with the Modified Coupled Line. IEEE Trans. Components, Packag. Manuf. Technol. 2012, 2, 1704-1710. [CrossRef]

37. Tang, C.-W.; Tseng, C.-T.; Chang, S.-C. Design of the Compact Tunable Filter with Modified Coupled Lines. IEEE Trans. Compon. Packag. Manuf. Technol. 2014, 4, 1815-1821. [CrossRef]

38. Feng, W.; Che, W.; Xue, Q. Balanced filters with wideband common mode suppression using dual-mode ring resonators. IEEE Trans. Circuits Syst. I Regul. Pap. 2015, 62, 1499-1507. [CrossRef]

39. Kim, P.; Chaudhary, G.; Jeong, Y. Ultra-High Transforming Ratio Coupled Line Impedance Transformer With Bandpass Response. IEEE Microw. Wirel. Components Lett. 2015, 25, 445-447. [CrossRef]

40. Garg, A.; Pratap, B.; Gupta, D. Design of Parallel Coupled Line Band Pass Filter. In Proceedings of the 2016 Second International Conference on Computational Intelligence \& Communication Technology (CICT), Ghaziabad, India, 12-13 February 2016; pp. 452-454. [CrossRef]

41. Wu, Y.; Cui, L.; Zhuang, Z.; Wang, W.; Liu, Y. A Simple Planar Dual-Band Bandpass Filter With Multiple Transmission Poles and Zeros. IEEE Trans. Circuits Syst. II Express Briefs 2017, 65, 56-60. [CrossRef]

42. Ahn, H.-R.; Tentzeris, M.M. Wideband and Compact Impedance-Transforming $90^{\circ}$ DC Blocks with Symmetric Coupled Transmission-Line Sections. IEEE Trans. Compon. Packag. Manuf. Technol. 2018, 9, 80-87. [CrossRef]

43. Bi, X.-K.; Cheng, T.; Cheong, P.; Ho, S.-K.; Tam, K.-W. Design of Dual-Band Bandpass Filters with Fixed and Reconfigurable Bandwidths Based on Terminated Cross-Shaped Resonators. IEEE Trans. Circuits Syst. II Express Briefs 2018, 66, 317-321. [CrossRef]

44. Saghir, A.; Quddious, A.; Arain, S.; Vryonides, P.; Nikolaou, S. Single-/Dual-BPF Using Coupled-Line Stepped Impedance Resonators (CLSIR). IEEE Trans. Circuits Syst. II Express Briefs 2018, 66, 1497-1501. [CrossRef]

45. Yang, Y.; Wu, Y.; Zhuang, Z.; Kong, M.; Wang, W.; Wang, C. An Ultraminiaturized Bandpass Filtering Marchand Balun Chip with Spiral Coupled Lines Based on GaAs Integrated Passive Device Technology. IEEE Trans. Plasma Sci. 2020, 48, 3067-3075. [CrossRef]

46. Zhu, L.; Sun, S.; Li, R. Microwave Bandpass Filters for Wideband Communications; John Wiley \& Sons: Hoboken, NJ, USA, 2011; Volume 232 